\title{
Role of Kairomones in The Management of Sal Borer (Hoplocerambyx Spinicornis) Population
}

\author{
Sunita Negi ${ }^{1}$ Raghubeer Singh Bhandari ${ }^{2}$ \\ ${ }^{1}$ Department of Zoology Govt,P.G.College Kotdwara-246149 Uttrakhand \\ ${ }^{2}$ Division of Entomology, FRI, DEHRADUN
}

Corresponding Author Email id: drsunitanegi09@gmail.com

Received: 06.12.2020; Revised: 21.02.2021; Accepted: 29.03.2021

OSociety for Himalayan Action Research and Development

\begin{abstract}
Hoplocerambyx spinicornis is a major pest of Sal which causes extensive damage to the Sal trees. As regard to the chemical control there is any likelihood of chemical control. The grub bores very deep into the heartwood and lodges itself inside chambers and galleries. Thus the present study deals with the multidisciplinary approach like the use of biocontrol agents (natural enemies), testing of kairomones, use of olfactrometer and the use of variously designed traps to manage the borers' population. Kairomone is the alternate chemical attractant which contain flavanoids, terpenoids and amine compounds. Such methods avoid felling of trees which are used in controlling pest population since decades. Above methods being eco friendly and environmentally sound could manage the pest population up to certain economic threshold level.
\end{abstract}

Keywords: Management $\bullet$ Hoplocerambyx spinicornis $\bullet$ Kairomones $\bullet$ Olfactrometer $\bullet$ Variously Designed Traps $\bullet$ Natural Enemies

\section{Introduction}

Though trap tree methods and other silvicultural practices have been used to manage insect in past but these process being resource hungry are need to be substituted by alternate economic and ecological approaches. Thus, realizing the potential of semiochemicals in monitoring and controlling insect pests, it become worthwhile to identify the volatile that become responsible for attracting insects. The identified attractant forms a basis for the development of suitable technology by using kairomones for saving the valuable Sal forests in an economic and eco-friendly way. Kaur et al. (2001) suggested that the fresh sap of the volatiles in the bast (secondary phloem+cambium) which when exposed broadcast attraction on all sites. Kaur et al. (2003) extracted nine essential oils compounds from he bast of Shorea robusta which are responsible for attracting the borer to the host tree, T-cadinol and $\alpha$-cadinol constitute the major portion of the bast oil $(37.72 \%)$ which is responsible for influencing host location for the heartwood borer. The present study includes multidisciplinary approaches like the use of natural enemies (biocontrol agents) and identification of kairomone, use of olfactrometer, and testing the efficacy of various designed traps as it avoids the tree felling for use in trap tree operation.

Though, there is no effective and practical method to control longicorn beetle larvae. Systemic insecticides injected into the tree are not a practical option in forest situations and even for individual tree the chemical is usually unable to reach those parts of the tree where the larvae are feeding.

\section{Material and methods}

Entomogenous fungi (Beauveria bassiana and Fusarium) were isolated from the infested larvae of $H$. spinicornis. Mass culture of fungi was 
prepared in the liquid medium with the help of Pathology Division,FRI which were then tested against the eggs, young larvae and mature larvae under the field and laboratory conditions.

Trap tree operation was carried out just after monsoon with the first shower of rain. For this one or two silviculturally unsound trees are felled per hectare of infested forest (depending upon the intensity and incidence of attack) and commercial $\operatorname{logs}$ are prepared up to girth of $20-30 \mathrm{~cm}$. Bark were then cut at both ends which were then beaten up to $30 \mathrm{~cm}$ to facilitate oozing of sap to provide shelter for the beetles. After this the portion is covered by the leaves or twigs of undergrowth etc. to avoid quick drying of bark. The beetles are collected from the traps regularly in the morning and evening daily and killed by putting them into containers having kerosene oil.

In kairomonal olfaction method the efficacies of extracts prepared from bast, heartwood and leaf oil were tested under the field and laboratory condition by using the kairomones trap and olfactrometer against the beetles during the peak period of emergence. Out of nine essential oils extracted from the bast of Shorea robusta, Tcadinol and $\alpha$-cadinol constituting (37.72\%) of bast oil was found responsible in influencing host location for the Sal heartwood borer. The interaction between volatiles of the bast of Shorea robusta and Hoplocerambyx spinicornis is considered as an important cue in influencing the host location for the borer.

The antennal response of beetles of $H$. spinicornis to the essential oils and ether extract of resin was determined using the EAG technique described by Dickens et al. (1983). EAG instrument (Model AMU 33; sensitivity 20X100) used in the study was procured from "Syntech Netherlands" by IICT Hyderabad

\section{Results and Discussion}

The insect (H.spinicornis) never comes out of the tree, there is no insecticide or chemical that can be used to control its spread. The only method known to check its growth so far is to catch the borer by setting tree traps by cutting fresh sal trees that attack the insect by its sap. Logs in the depots are treated with endosulfon in order to kill the emerging insect during the monsoon. Endosulfon was effective against Sal borer, But logs covered or prevented from rain by polythene that prevents it from dilution with rain.

EAG studies were conducted in IICT, Hyderabad which shows direct interaction at the receptor level between plant odors and the response to sex attractant. Micrographs show that $4^{\text {th }}$ and $5^{\text {th }}$ antennal tip has finger like projections, which are chemosensory in nature. These sensilla are arranged in a row have comb like hairy lining. In the root of these sensilla there is a peg and bulge like structure, which has fine sensory lining of cups, which perceives the chemical sense. The number of sensilla that are presumed to ranged from 12000-50,000 on the antennae. With the help of these olfactory sensillum beetle can recognize aromatic compound present in leaves, bark and trunk. Chemoreceptor sites of female and male antennae are different in numbers and types as indicated by different EAG responses to each of the material tested. Female antenna possesses greater number of chemoreceptor sites than male antenna due to higher EAG responses.

EAG results (Table:1) shows that materials (Leaf Oil, Bast Oil, Heartwood Oil and Ethereal Extract) assayed elicited EAG response of antennae of both the male and female beetles. However, female and male antennae responded differently to these materials as evident by the higher EAG responses of the former then those of the latter. Considering the amplitude $\geq-0.5 \mathrm{mV}$ as EAG response, tip of the female antenna was found to show the response to all materials and response was observed to decrease in the order $\mathrm{LO}>\mathrm{BO}>\mathrm{HO}>\mathrm{EER}$, while tip of the male antenna responded to $\mathrm{LO}$ and $\mathrm{BO}$ and the response elicited by $\mathrm{LO}$ was greater than that of $\mathrm{BO}$. Among all the tested materials $\mathrm{LO}, \mathrm{BO}$ and $\mathrm{HO}$ elicited response to base portion of the female antenna and EAG activity of $\mathrm{BO}$ was the highest followed by the LO and $\mathrm{HO}$. Base of the male antenna responded to LO only. No EAG activity was found to be 
associated with the middle portion of the antenna of both the sexes as EAG responses shown by this part of the antennae were less than that of control or $<-0.5 \mathrm{mV}$. Kairomone is the alternate attractant (Fig 1) .The qualitatively analyzed extract of freshly collected bark was tested for functional group which revealed the presence of good amount of terpenoids, flavnaoids and amine compounds. The TLC of this extract revealed a good amount of flavanoids

Table 1: EAG responses of $H$. spinicornis to the volatiles of $S$. robusta

\begin{tabular}{llcccccc}
\hline Sl. no & Test material & \multicolumn{5}{c}{ EAG (-mV) } \\
\cline { 3 - 8 } & & \multicolumn{3}{c}{ Female antenna } & \multicolumn{3}{c}{ Male antenna } \\
\cline { 3 - 7 } & & Tip & Middle & Base & Tip & Middle & Base \\
\hline $\mathbf{1}$ & Leaf Oil & 2.327 & 0.00 & 1.211 & 1.391 & 0.118 & 1.529 \\
$\mathbf{2}$ & Bast oil & 2.276 & 0.169 & 1.680 & 0.786 & $<$ control & 0.390 \\
$\mathbf{3}$ & Heartwood oil & 1.640 & $>$ control & 0.722 & 0.482 & $<$ control & 0.273 \\
$\mathbf{4}$ & Etheral Extract & 0.745 & $<$ control & 0.123 & 0.318 & $<$ control & $<$ control
\end{tabular}

The condensed material of this crude extract when sequentially separated on silica gel column resulted in brown, yellow and white compounds in good quanitity. Brown colored compound attracted more number of insects than others

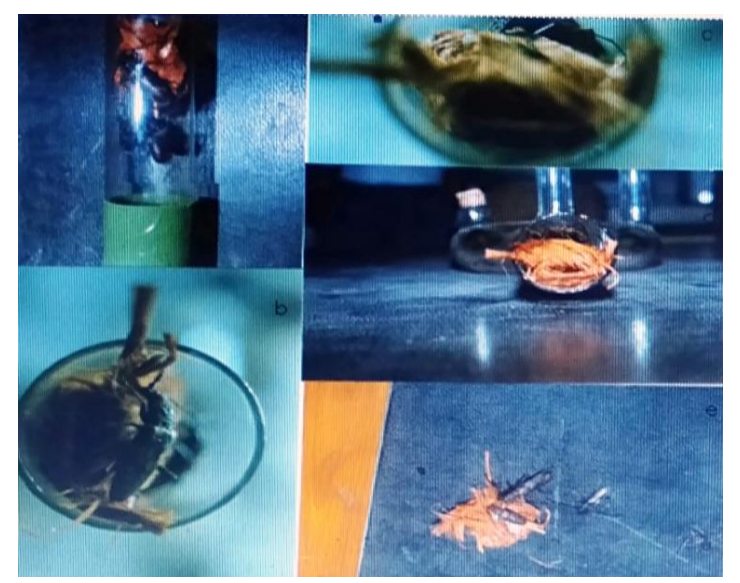

(a- Testing against $\alpha$ - cadinol; b- Testing against T- cadinol; c- Testing against bast oil; d- Beetles at the mouth of olfactrometer; e- Testing against heartwood oil)

Fig 1: Laboratory studies with Kairomones extracted from the bast and heartwood of Shorea robusta against Holpocerambyx spinicornis
Beauveria bassiana) recorded for the first time from the larvae of H.spinicornis from

Uttrakhand as well as from Madhya Pradesh, which were found very effective against egg, young larvae, and mature larvae as the grubs are attacked by the fungus.

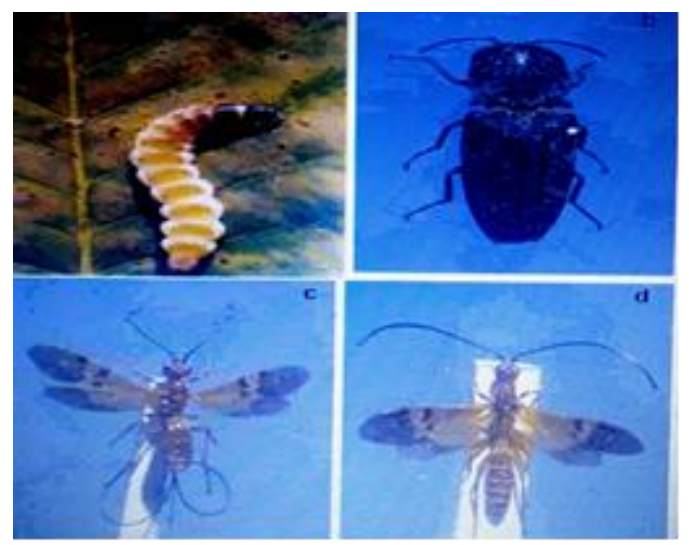

(a- Larva of Alaus sordiduc; b- Adult beetle Alaus sordiduc; c\&d- Exobraeon maculipennis (Female and male)

Fig 2: Natural enemies of Hoplocerambyx spinicornis

Efforts have also been made to explore and survey the natural enemies available in the infested areas which could control up to some extent the population of Sal borer. It could be possible only 
if these should be mass reared and released at appropriate sites after extensive stages. Natural enemies (Fig 2) consisting of parasitoids, predators and insect pathogens also play an important role to influence the population of sal borer. Alaus sordidus (Beeson 1928) (Coleoptera: Elateridae) is one of the effective predators, which destroys the larvae, pupae and immature beetles of the Hoplocerambyx, is Black Elaterid beetle. Insect predators Alaus sordidus.nocturnal in habit and is attracted towards light. Their populations remain prevalent upto $3^{\text {rd }}$ week of June and thereafter scanty by July when rainfall was more frequent. Three larval parasitoid were recorded Exobracon maculipennis, Disophyrs dehraensis, Iphialux immsi.. All belongs to Order Hymenoptera and family Braconidae. None of them were found effective during outbreak.

\section{References}

Beeson CFC (1928): The Trap Tree Method. Ind. For. 54: 595-599.

Dickens J C, Gutman A, Payne T L, Ryker L C, Rudinsky J A (1983): Antennal olfactory responsiveness of Douglas fir beetle, Dendrocalamus pseudotsugae Hopkins (Col: Scolytidae) to pheromone and host odors J. Chem Ecol. 9: 1383-1395.

Gusain S (2004): Ecobiology of Hoplocerambyx spinicornis, Newm. (Coleoptera: Cerambycidae) with special reference to community structure and microclimate. D. Phil thesis submitted to FRI Deemed University.

Kaur S, Dayal R., Varshney VK, Bartley JP (2001): GC-MS analysis of Essential oils of Heartwood and resin of Shorea robusta. Planta medica 67, 883-886.

Kaur S, Varshney VK., Dayal R ( 2003): GC-MS analysis of essential oil of Shorea robusta bast. J Asian Nat. Prod.Res. 5(3), 231234.

$$
* * * * * * *
$$

